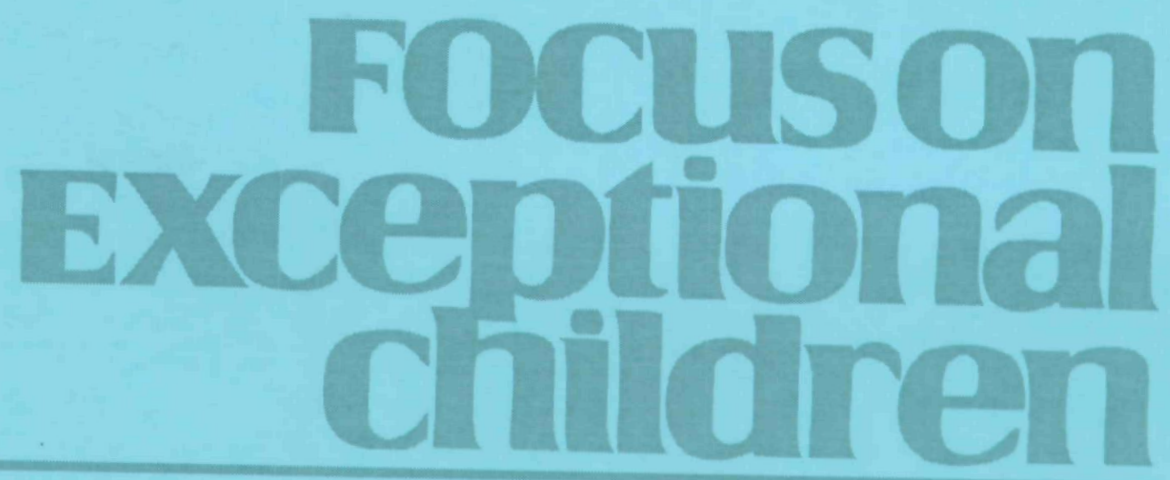

\title{
A Comprehensive Approach to Improving Reading Fluency for Students with Disabilities
}

\author{
Jill H. Allor and David J. Chard
}

Learning to read in any alphabetic language involves learning the associations between the symbols and the sounds that those symbols represent in speech (Adams, 1990). To become a proficient reader, however, a student has to learn to perform this process quickly and accurately enough for words and phrases to sound like language so that the language can be understood. For many students with disabilities, word identification problems slow their reading to the extent that they are unable to fully comprehend the passages they are reading. Slow and effortful reading hampered by word identification problems is an indication of poor fluency (Samuels, 2002).

It is easy to assume that fluency problems lead to comprehension problems. Essentially, it is hard to understand what you cannot read. However, the relationship between fluency and comprehension is complex. In fact, some research suggests that fluency has a reciprocal relationship with comprehension, each fostering the other (Stecker, Roser, \& Martinez, 1998). It is with this relationship in mind that Pikulski and Chard (2005) defined fluency in this way:

\footnotetext{
Reading fluency refers to efficient, effective word recognition skills that permit a reader to construct the meaning of text. Fluency is manifested in accurate, rapid, expressive oral reading and is applied during, and makes possible, silent reading comprehension. (p. 3)
}

We believe this definition takes a "deep construct view" (Chard, Pikulski, \& McDonagh, 2006, p. 40) of fluency, rather than a surface view in which fluency is perceived only as encompassing the rate and accuracy of reading. This definition makes fluency part of the developmental process of building oral language and decoding skills required for reading comprehension, resulting in a construction of the relation between reading comprehension and fluency as reciprocal and causal.

Efficient and accurate decoding is directly related to comprehension. When a student with disabilities struggles to read words and sentences fluently, it is difficult to understand what is being read. Conversely, when a student struggles with oral language and listening comprehension, building efficient word reading skills is more difficult. Therefore, it is critical to approach reading instruction comprehensively to improve reading fluency for students with disabilities. Students with learning disabilities (LD) may struggle primarily with phonologically based skills, or they may experience significant difficuity with both

Dr. Allor is an associate professor and chair of the Department of Teaching and Learning, and Dr. Chard is the Leon Simmons Endowed Dean of the Simmons School of Education and Human Development at Southern
Methodist University.

Copyright $(\odot$ Love Publishing Company, 2011 
phonologically based skills and broader language skills; however, even if the primary disability is with basic decoding skills, instruction should still include linking those skills with meaningful language. Students with intellectual disabilities (ID) typically experience significant difficulty in both areas and require intense instruction in decoding and general oral language development.

\section{A CONCEPTUAL FRAMEWORK FOR READING FLUENCY}

Successful reading is a complex interaction of language, sensory perception, memory, knowledge, and motivation. Perfetti, Landi, and Oakhill (2005) described the process of reading from word identification to text comprehension using the diagram in Figure 1. This diagram helps us to understand just how complex reading is to learn and to do. The box at the lower left hand corner of the diagram represents the process of transforming print (via visual input) to speech and into meaningful words. This word identification process is supported by both the reader's knowledge of letter-sound associations and recognition of the meaning of the

\section{FOCuson Exceptional children}

ISSN 0015-511X FOCUS ON EXCEPTIONAL CHILDREN (USPS 203-360) is published monthly except June, July, and August as a service to teachers, special educators, curriculum specialists, administrators, and those concerned with the special education of exceptional children. This publication is annotated and indexed by the ERIC Clearinghouse on Handicapped and Gifted Children for publication in the monthly Current Index to Journals in Education (CIJE) and the quarterly index, Exceptional Children Education Resources (ECER). The full text of Focus on Exceptional Children is also available in the electronic versions of the Education Index. It is also available in microfilm from Serials Acquisitions, National Archive Publishing Company, P.O. Box 998, Ann Arbor, MI 48106-0998. Subscription rates: individual, $\$ 50$ per year; institutions, \$68 per year. Copyright (C) 2011, Love Publishing Company. All rights reserved. Reproduction in whole or part without written permission is prohibited. Printed in the United States of America. Periodical postage is paid at Denver, Colorado. POSTMASTER: Send address changes to:

$$
\begin{gathered}
\text { Love Publishing Company } \\
\text { Executive and Editorial Office } \\
\text { P.O. Box } 22353 \\
\text { Denver, Colorado } 80222 \\
\text { Telephone (303) 221-7333 }
\end{gathered}
$$

\section{CONSULTING EDITORS}

Steve Graham Vanderbilt University
Ron Nelson University of Nebraska-Lincoln

Eva Horn

University of Kansas
Carrie E. Watterson Senior Editor
Stanley F. Love Publisher word once it is identified. The box at the upper left hand corner of the diagram is the text comprehension box, representing the process of stringing meaningful words together to create sentences, to make sense of those sentences, to draw inferences from the author's message, and to connect them to existing knowledge of the world. When fluent readers actively engage with text, they apply their knowledge of the language to make sure that multisyllabic words are accurately decoded and that the sentences they are reading make syntactic sense. As they read, their general knowledge increases, which, in turn, increases their word knowledge, making it easier to understand passages that will be read in the future. In other words, fluent readers grow in all of the skills that contribute to fluency and in fluency itself. This is not the case for readers who are not fluent, as they are less likely to read extensively because they find reading difficult and unmotivating. By reading less, they do not learn at the same pace as their peers, and their reading skills, along with their general knowledge, are likely to fall further and further behind (Stanovich, 1986).

In order for reading to proceed effectively, the reader cannot focus attention on both word identification and comprehension. Understanding an author's message involves making inferences, responding critically, and so on, and it always requires attention. The dysfluent reader can alternate attention between the two processes; however, this makes reading a laborious, often punishing process. If attention is drained by decoding words, little or no capacity is available for the attention-demanding process of comprehending. Therefore, automaticity of decoding - a critical component of fluencyis essential for high levels of reading achievement.

In an early description of the relationship between the lower level processes involved in word identification and the higher level processes involved in reading comprehension, Perfetti (1985) posed a "verbal efficiency theory" which suggests that lower level processes (e.g., word identification) must reach a minimum performance level before higher level processes can be performed simultaneously during reading. According to Perfetti's theory, when lower level processes are performed inefficiently, higher level processes will attempt to compensate. This means that, when students are not fluent, they tend to rely on their ability to guess at and make sense of words based on context and their vocabulary. Ultimately, this approach breaks down as text grows increasingly complex and the words used in texts outgrow the reader's vocabulary. Perfetti's theory assumes that learning and practice may enhance efficiency and reduce demands, resulting in more cognitive attention to devote to comprehension.

\section{TEACHING LOWER LEVEL PROCESSES}

Using Perfetti's blueprint as a guide, it is important to consider the instructional first steps to helping a student with 


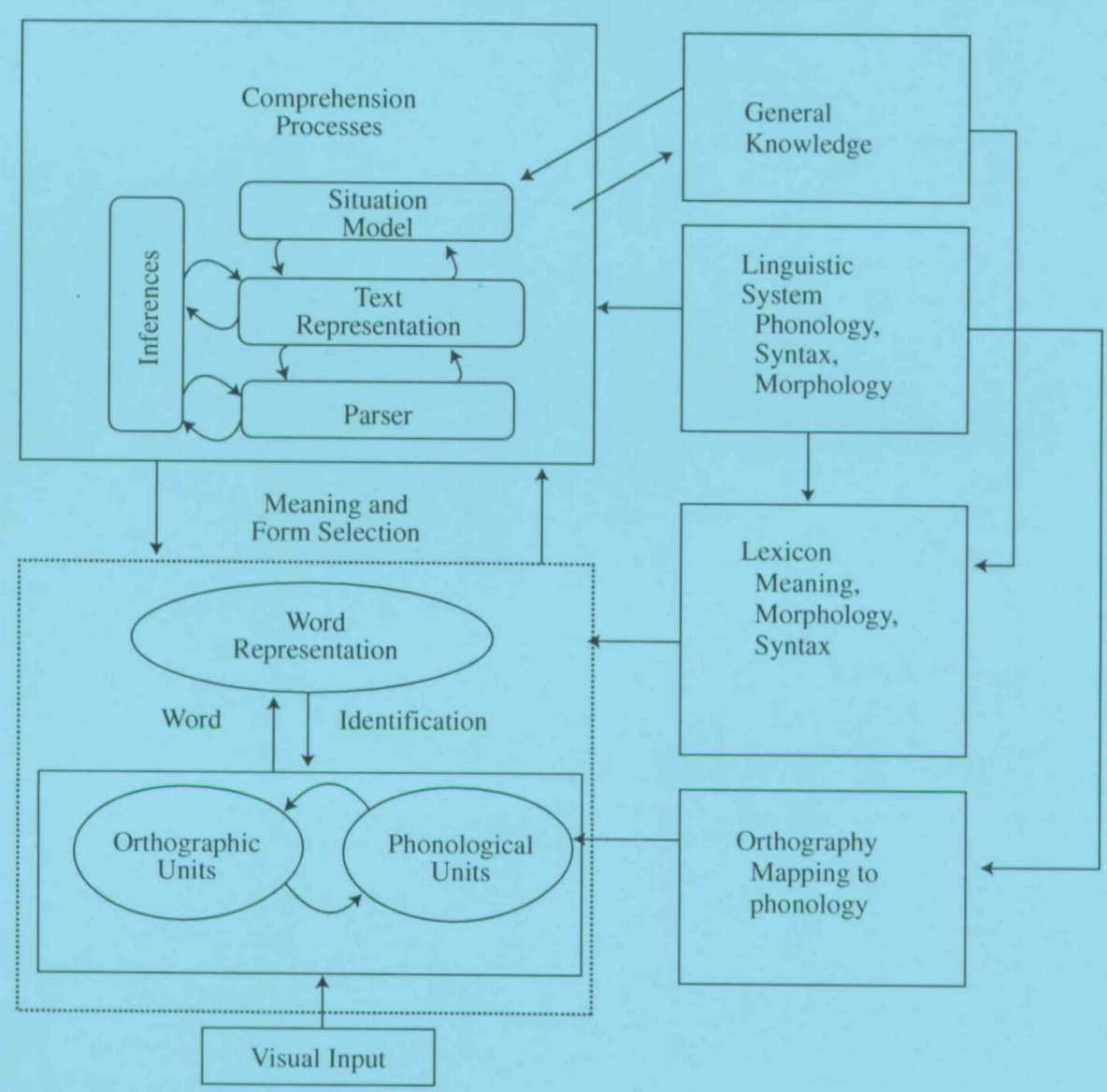

Source: From "The Acquisition of Reading Comprehension Skill" (pp. 227-247), by C. A. Perfetti, N. Landi, \& J. Oakhill, 2005. In M. J. Snowling \& C. Hulme (Eds.), The Science of Reading: A Handbook. Oxford, UK: Blackwell. Copyright 2005 by Blackwell. Reprinted with permission.

FIGURE 1.

Components of Reading Comprehension from Identifying Words to Comprehending Texts

disabilities develop accuracy and automaticity with the building blocks of reading, specifically, phonemic awareness, letter-sound associations, word blending, and word identification. Tallal, Merzenich, Jenkins, and Miller (1999) proposed a compelling set of principles that should be considered when designing classroom instruction and interventions for working with students with disabilities. These principles were identified because they not only address the nature of the task (i.e., basic associations), but they consider the need for students to be attentive to details to develop automaticity.

The principles include the following:

1. The student must attend closely to features of the sensory task. This suggests that both visual and auditory communication must be clear and unambiguous for the student.
2. The student must maintain attention to be able to perform the task at a high level of accuracy (if the task is too difficult, learning cannot be achieved). It is important to ensure that the student (e.g., blending sounds to make a word) is likely to be successful at the task by teaching all of the prerequisite skills.

3. The student's behavior (i.e., skills associated with emergent and early reading) must be reinforced in a highly consistent and rewarding manner to maintain motivation and drive learning through corrective feedback. Students who struggle to learn to read require intense amounts of practice; therefore, special care must be taken to ensure that motivation is maintained.

4. Highly consistent, repetitive input must be given over an intense period of time so that consistent patterns 
of neuronal activation occur repetitively, building specific stimulation patterns to "represent" the input from the environment in the brain. This principle seems to suggest that accurate practice is particularly important to develop automaticity within the word identification box in the Perfetti model.

5. Once a behavior is established (i.e., the response is accurate and consistent), learning can be driven most effectively by systematically increasing the difficulty of the task as performance improves. As a student demonstrates increasing proficiency with a skill or set of skills, it is important to integrate those skills into more difficult tasks. The importance of challenging students with disabilities as their word recognition skills develop has been illustrated empirically in the classroom (e.g., Chard \& Harn, 2008) and supports the ideas posed by Stanovich (1986) and Ehri (2005) that reading more both challenges readers and improves their fluency.

The principles set forth by Tallal et al. (1999) illustrate how instructional design should be developed when teaching word identification, which is the foundation of fluency. Specific instructional approaches that employ the principles will be discussed later in this article. However, we must also ensure that students with reading disabilities are receiving support in the other areas of the model.

\section{TEACHING HIGHER LEVEL PROCESSES}

In addition to the lower level processes indicated in the lower left hand corner of the reading blueprint in Figure 1, it is important to simultaneously teach and support higher level processes including oral language development and comprehension. This allows students to develop a foundation in language skills so that they become familiar with the meanings of phrases with increasingly sophisticated syntax. Reading and understanding what we read supports vocabulary development (Baumann \& Kame'enui, 2004; Stanovich, 1986). However, developing the oral language and vocabulary skills of children is one of the greatest challenges facing us as educators, particularly for those children who are learning English as a second language or who spend their preschool years in language restricted environments.

Reading fluently is dependent on being familiar with words in their spoken form. If words are to be recognized when they are read, they must be part of what the reader knows through oral language development. Unless a printed word triggers a reader's phonological memory for the word and the syntactic and meaning aspects of the word, it cannot be fluently decoded or read. In short, fluency is just as dependent on the reader's vocabulary as on his or her decoding skills (Chard et al., 2006). So, when we read fluently, we read more, understand more, and build our vocabulary. Simultaneously, we read fluently when we have more word knowledge. This is the reciprocal relationship between reading fluency and vocabulary/comprehension.

The remainder of this article explains how to translate these principles into effective instructional practices that will increase the likelihood that students with disabilities will become fluent readers who are able to successfully construct meaning as they read. Recognizing that multiple factors impact fluent reading, we specifically address how teachers can foster the development of both lower order and higher order processes. Throughout the article, we provide examples of techniques and strategies, explaining how they work together to support fluent reading. We first explain generally how the aforementioned learning principles relate to fluency instruction. We then provide recommendations about assessing fluency development and setting goals. Finally, we discuss specific methods for selecting and designing activities for fluency development.

\section{PRINCIPLES FOR PLANNING EFFECTIVE FLUENCY INSTRUCTION}

As is evident by now, designing effective fluency instruction is complex and challenging, as it must address both lower and higher order processes in an integrated manner, gradually leading to fluent reading that enables students to fully process the meaning of text. When students read fluently, they are free to focus on comprehension rather than underlying lower order processes. Planning effective fluency instruction involves building automaticity with a variety of underlying skills, as well as building fluency with connected text. It is key that students not only learn the sounds of letters (e.g., they must identify these sounds automatically without great effort and then use these sounds quickly to learn new words), but also new words must then become automatic and applied within sentences and passages. In much the same way musicians practice individual notes and phrases, readers must practice discrete skills and combine those discrete skills into words, phrases, and passages, eventually becoming fluent readers who read with deep comprehension and expression. In this section, we explain how to apply six learning principles when planning effective fluency instruction. These principles are consistent with the research and conceptual framework previously described and include five principles identified by Tallal et al. (1999). We have added a sixth principle to address the need to imbed fluency instruction in meaningful contexts as is consistent with the conceptual framework previously proposed. When these principles are applied during instruction, they are interconnected and work in concert to enable students, particularly those with disabilities, to benefit from fluency instruction.

\section{Attend Closely to Task}

The first learning principle we will highlight is the necessity for students to attend closely to the features of the 
learning task (Tallal et al., 1999). As is the case with many educational principles, this idea is rather obvious, yet it is often difficult to achieve, particularly for students with disabilities. Students with disabilities are often easily distracted from a task or experience difficulty determining which part of a task is most important. Special educators need to ensure that students know where to focus attention and that students are provided with reinforcement and prompts so they maintain attention. Similar to the music conductor who uses a baton to provide the musicians with cues, providing clear cues during group instruction is one way teachers ensure that students attend closely to a task. For example, when teachers conduct an activity that targets building fluency with individual words, they teach their students that when they move their finger underneath a word, the students are to think of the word, and when they tap on the word, the students are to say the word aloud in unison. The cues of pointing and tapping enable students to focus attention on the specific item they are practicing so they are able to build fluency with that item. This type of instructional procedure is common among programs based on direct instruction principles and effective for students with disabilities (Kame'enui, Carnine, Dixon, Simmons, \& Coyne, 2002; Carnine, Silbert, Kame'enui, \& Tarver, 2004). Using cues allows teachers to ensure that all students are focused and practicing a skill, even during unison responses.

In addition to logistical procedures such as cuing, teachers also need to provide explicit instruction about the purpose of activities and the critical components of activities. They need to explicitly focus the students' attention on how the task is accomplishing a specific purpose. For example, teachers need to explicitly teach students the relationship between comprehension and fluency. They must be taught that when they think about the meaning of a passage, they will be better able to read with expression (i.e., prosody). When teachers model reading with expression, they should explicitly remind their students to pay attention to the way they are reading the story by explaining that they are reading the story as if they are telling the story to someone rather than just saying words quickly. Reading with expression is a critical component of fluent passage reading. In sum, teachers need to verbally direct student attention to a critical task or component of a task.

\section{High Level of Accuracy}

The second learning principle to consider is the need for students to maintain a high level of accuracy (Tallal et al., 1999). Frequent errors decrease the likelihood that fluency will develop; therefore, tasks should be selected in which students are expected to answer most items correctly. Care should be taken to ensure that students have already mastered the prerequisite skills to be successful with the new task. For students with disabilities, this usually means that a new task includes the review of skills already mastered with only one new element introduced. This is very straightforward when practicing lower order skills, such as letter-sound knowledge. Only one new letter-sound should be introduced in a lesson and typically that letter-sound should be practiced (along with previously learned lettersounds) until it is mastered (i.e., usually at least 2 to 3 days for students with LD, oftentimes longer for students with ID). This is more challenging and subjective with higher order skills, such as listening comprehension. In this case, teachers must make more complex decisions, such as determining the appropriateness of passages that are to be read to their students. For example, are the students ready to make the inferences required to understand the text? Is the vocabulary too difficult? Is the topic outside the life experiences of the students?

To ensure that fluency is developing, student performance should be monitored carefully to determine whether students are maintaining a high level of accuracy. Even after careful selection of skills and activities, the performance of students with disabilities is often unpredictable. If accuracy is not high, teachers should act immediately by providing scaffolding to support students. If accuracy is less than $90-95 \%$, the tasks should be changed as soon as possible. If students have clearly mastered a skill (e.g., with lower order skills, students should be able to respond correctly and quickly for a skill to be considered mastered), teachers should praise students for their success and adjust the activity to include more challenging items. Often it is much easier to move to a more challenging task than it is to move to a less challenging task, as students quickly become discouraged when they realize they are unable to be successful with the task presented to them. The amount of practice needed varies tremendously among students with disabilities. Some students require much more practice on a particular skill than other students. In most cases, students with LD require fewer repetitions than students with ID, and students with higher IQs require fewer repetitions than students with lower IQs. But these are general trends, and individual student performance is not always consistent with these trends. For example, in our research with students with ID, some students with lower IQs unexpectedly required less practice than some students with higher IQs (Allor, Mathes, Roberts, Cheatham, \& Champlin, 2010). It is imperative that teachers monitor performance so they are able to respond to student performance appropriately.

\section{Motivation}

Several factors should be considered to ensure that students are motivated to participate actively in fluency instruction and routinely read a wide variety of text. Fluency development for students with disabilities requires extensive practice; therefore, students with disabilities must maintain high levels of motivation if they are to become fluent readers. First, students need to view reading as a meaningful task 
that can be interesting and relevant to them. Some students come to school excited to learn to read and motivated to locate and read books that interest them. For other students this is not the case, particularly if they have experienced failure and frustration as they have attempted to learn to read. As students are able to read a wider variety of text, teachers have increasing opportunities to assist students in finding text to read that is meaningful to them. Assisting students as they search for text that is both appealing and at an appropriate level of difficulty is an important task for teachers. Related to this idea is that students must see how participation in instructional activities is leading to more opportunities to read text that is important to them. They need to see that they are improving and that the improvement they are making is leading to faster, easier, and more meaningful reading. Students benefit from monitoring their own progress. For example, involving students in setting goals is an effective technique for improving motivation.

Until students are motivated to read intrinsically, praise and tangible reinforcers are extremely important-both during instructional activities and to reinforce students for reading independently. Teachers should reinforce on-task behaviors through specific praise (e.g., "Everyone said the word when I tapped it. Great!"), but, as teachers are well aware, providing cues and praising students for following these cues is often not enough to ensure students remain engaged. Many students with disabilities require tangible reinforcers such as points, marbles in a jar, small rewards, and the like. We have already discussed the importance of maintaining high rates of success to optimize learning, but it is also important to recognize the role of success in maintaining motivation. If students make too many errors during reading and instructional activities, they will become frustrated. Finally, consistency is another key to maintaining students' attention. When teachers use the same cues across time and across activities, students are much more likely to maintain attention because they are able to quickly determine exactly what is expected of them. When students become accustomed to success, they are more likely to remain actively engaged in a task and focused on the target skill.

\section{Intensity}

Maintaining high levels of intensity is another learning principle that is deceptively difficult to achieve. While it seems obvious that students with disabilities require extensive practice to become successful fluent readers, increasing the amount of time students spend practicing is challenging. It is also challenging to decide exactly which skills to practice and how much to practice them. As previously discussed, practice should include a variety of discrete skills (e.g., fluent letter-sound correspondence, fluent sounding out, unitization of individual words), as well as passage reading. In today's schools, many different activities and responsibilities compete for student and teacher time. Further, students with disabilities often require support during practice, and resources for this support are limited. Clearly, administrators and teachers should allocate adequate time to reading instruction, but they should also take care that other activities and responsibilities do not interfere with the time that is set aside for reading. Further, teachers need to ensure that allocated time is used as wisely as possible. During group instruction, several instructional techniques can be used to increase time on task. For example, pacing for lower order skills should be very quick because student responses during these tasks should gradually become automatic. Typically, multiple brief tasks should be conducted within a single lesson so students receive cumulative practice across several skills within a short amount of time. Although teachers should introduce new skills and plan all instructional activities, students should also practice skills independently or with the support of someone other than a teacher, such as family members, paraprofessionals, volunteers, or peers.

\section{Appropriate Level of Difficulty}

As is demonstrated clearly by the diagram in Figure 1, the skills involved in fluent reading are varied, complex, and interrelated. Both lower and higher order skills must be addressed simultaneously. Fortunately, research regarding systematic and explicit instruction, particularly with lower order skills, provides a clear understanding of how these skills develop (see Adams, 1990; Ehri, 2005). Although the scope and sequence of skills in many programs is often found buried in the back of a teacher's guide, teachers should familiarize themselves with the scope and sequence so they can adequately monitor student progress within the curriculum and ensure that, as students become more proficient, the tasks become appropriately more difficult and complex. Discrete skills are integrated and applied to isolated word recognition and, ultimately, passage reading. In Figure 2, we provide a broad overview of the instructional strands that must be addressed as students learn to read. The grade levels across the top of the figure represent the grade in which the skills are typically developed. With appropriate support and intensity, at-risk students and students with learning disabilities should be able to achieve benchmarks at or near the same time these benchmarks are achieved by their typically-developing peers. Students with ID will likely require more time to achieve these skills; however, research is demonstrating that with intensive, individualized instruction they acquire these skills in a similar manner and sequence (Allor, Champlin, Gifford, \& Mathes, 2010; Allor, Mathes, Jones, Champlin, \& Cheatham, 2010; Allor, Mathes, Roberts, et al., 2010). In other words, the progression of the development of skills is similar. As can be seen in Figure 2, vocabulary and comprehension skills should be addressed through oral language (i.e., listening and speaking) activities until students have acquired sufficient lower order skills with print. As students become more skilled in 


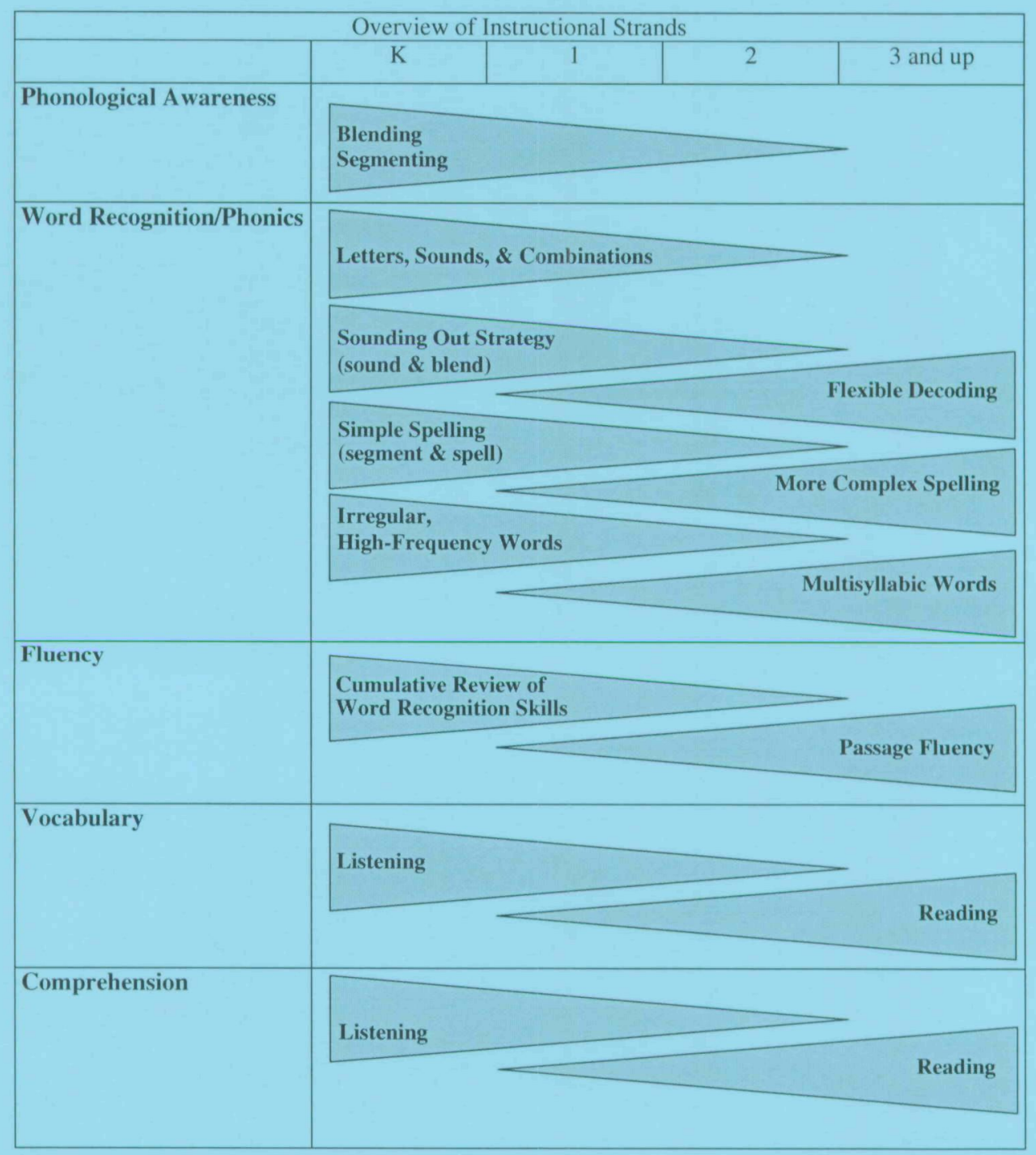

\section{FIGURE 2.Overview of Instructional Strands}

word identification, vocabulary and comprehension are typically associated with reading tasks. This shift should be gradual to ensure that vocabulary and comprehension skills are progressing, even if students are not yet skilled in word identification.

\section{Practice Meaningful to Students}

The final principle is to ensure that fluency activities are as meaningful as possible to students. As discussed in the introduction to this article, research indicates that the relationship between higher and lower order processes is reciprocal. For example, it appears that students with stronger vocabularies tend to develop phonemic awareness (PA) more easily. This is logical when you consider a specific PA task. Would it be easier for a child to blend $/ \mathrm{d} / \mathrm{o} / / \mathrm{g} /$ into the word $\operatorname{dog}$ or blend $/ \mathrm{n} / / \mathrm{a} / / \mathrm{b} /$ into the word $n a b$ ? More than likely, a child would find the word dog easier because the meaning of the word is probably much more familiar than the meaning of the word nab. Similarly, it is easier for students to sound out words that are in their spoken vocabulary. When lower order processes are applied to meaningful tasks, both success and motivation are increased, improving the likelihood that students will become fluent in lower order skills. In turn, this will lead to the higher order skill of reading with prosody, an outward expression of comprehension. Additionally, students are more likely to view reading as a meaning-making activity that includes recognizing words as opposed to solely a word identification activity. 


\section{ASSESSMENT AND GOAL SETTING}

Determining whether a student reads fluently or not is relatively simple. It is easy to calculate the percentage of words read correctly in a passage and the rate at which a passage is read (i.e., number of correct words per minute). It is also relatively straightforward for a teacher to judge whether a student is reading with appropriate prosody (i.e., expression). However, when a student is dysfluent, the challenge is in determining which underlying skill or combination of skills is negatively impacting fluency and prohibiting the reader from deeply comprehending text. Ironically, while it is relatively easy to identify a fluency problem, it is extremely challenging to diagnose the cause of the problem and to plan instruction to address the cause. This irony has led to much debate over the appropriateness of simple measures of accuracy and rate, such as the oral reading fluency (ORF) measure of Dynamic Indicators of Early Literacy Skills (DIBELS; Good \& Kaminski, 2002). It is critically important to view ORF (whether it is the DIBELS measure or another similar measure) as an indicator of a problem and not a diagnosis. It is comparable to a doctor taking a child's temperature. A fever indicates there is a problem, but it does not inform the doctor as to the best method of treating the problem.

ORF measures should be used for two primary purposes. First, they should be used to determine early whether a child requires additional support to reach benchmarks. Second, they should be used to monitor student progress toward benchmarks. Appropriate benchmarks are available from multiple sources. Generally, students should be reading approximately 40 to 60 words per minute by the end of first grade (on ending first-grade level passages). Slow, labored reading severely inhibits comprehension, necessitating intensive intervention. Across the primary grades, students gradually increase their speed until they are able to read approximately 120 to 140 words per minute on grade level text by the end of fifth grade. Once this level is established, instruction should include continued practice reading a wide variety of texts, focusing on comprehension rather than faster reading. If students are performing below expected benchmarks, further assessment is needed to determine the specific skill or set of skills that need to be addressed to improve fluency. These include skills within all of the strands outlined in Figure 2; however, the most likely culprit for students with LD is in the area of word recognition or the alphabetic principle. Research repeatedly demonstrates that deficits with the alphabetic principle are at the core of most reading disabilities (Stanovich, 2000; Wagner \& Torgesen, 1997). In contrast, students with ID are likely to experience difficulty in all areas included in Figure 2. Once target skills are identified (e.g., decoding regularly spelled words), then progress on those target skills should be measured in addition to ORF. If the target skill is decoding regularly spelled words, then using Nonsense Word Fluency (NWF) from DIBELS or a similar measure is helpful to measure progress. It is likely that, as students focus on decoding, their ORF scores may decrease slightly as they slow down to apply their developing skills. ORF scores typically will begin improving after NWF scores near benchmark levels. It is important to measure progress on component skills of fluency to ensure that students are making progress and to prevent students from becoming discouraged when their ORF scores temporarily decrease. Goals for component skills and for overall oral reading fluency should be set with the student, and progress should be monitored.

\section{METHODS FOR SELECTING AND DESIGNING ACTIVITIES FOR FLUENCY DEVELOPMENT}

In this section we describe how to select and design activities that incorporate the instructional principles just described and are consistent with current empirical research and the conceptual framework we explained in the beginning of this article. Instruction should address multiple skills concurrently, and the relationships among these skills should be clear to teachers so they are able to teach students to strategically combine a variety of skills with increasingly more complex tasks. Effective teachers are able to arrange instructional activities so that skill in one area positively influences skill in another area. For example, students will be more successful with phonemic awareness activities when the words practiced during these activities are words that are meaningful to them. Likewise, including some new vocabulary words during phonemic awareness activities provides an additional opportunity to briefly review the meanings of these words. In this section, we describe the fluent development of key skills, ending with a discussion of how to integrate these skills during instruction. Of course our discussion here will provide only a brief overview of recommendations and will focus on building automaticity. Many resources are available (see Carnine et al., 2004; O’Connor, 2007).

To facilitate this discussion, consider the overview in Figure 2 of the primary skills that must work together to result in fluent reading for meaning. The patterns of development for students with disabilities vary depending on the type and severity of their disability, as well as the timing and appropriateness of intervention. If the need for additional support is identified early and intensive intervention is provided immediately, many students with $\mathrm{LD}$ or at risk for developing LD will follow a pattern of development that is similar to typically developing peers. Students with ID will require more time, but research indicates that they will follow very similar patterns of development at a much slower pace (Allor, Mathes, Roberts, et al., 2010). Older students who did not receive sufficient support as they were learning to read are likely to have developed skills in some areas but not others. For example, they may have memorized a fairly large number of words by sight and overrely on context clues, but they may not have developed full alphabetic 
skills. Typically, when this is the case, students experience extreme difficulty decoding multisyllabic words, particularly the content words required when reading content area text, such as science or history text. In the sections below, we make recommendations for students with various needs.

\section{Phonemic Awareness}

The ability to fluently blend individual sounds into spoken words (i.e., blend $/ \mathrm{cl} / \mathrm{a} / / \mathrm{t} /$ into $c a t$ ) and to fluently segment spoken words into their individual sounds (i.e., segment cat into its individual phonemes, /c/ /a/ /t/, saying each sound separately) are two key PA skills that, when combined with other skills, lead to fluent word recognition that enables comprehension. Typically, in preschool and early kindergarten, these skills are taught orally without print and later connected to print as students acquire letter knowledge. The goal, however, is for students to apply blending and segmenting to decoding (i.e., sounding out) and spelling tasks (i.e., segmenting spoken words into phonemes and then writing letters to represent those phonemes). All of the principles previously discussed can be applied to PA instruction. For example, if students have difficulty blending and segmenting, the task can be made simpler by selecting words that begin with continuous sounds and are likely to be familiar to students (e.g., feet). Another way to ensure the activity is meaningful is to select words from a book after reading the book aloud to students. As soon as students know some letter-sounds, words can be selected that are also regularly spelled (e.g., sit, man), and explicit connections can be made to help students connect the abstract skills of blending and segmenting to the more concrete skills of sounding out printed words and spelling those words.

\section{Letter-Sound Correspondence and Decoding}

Identifying the sounds represented by individual letters and combining those sounds to form words are lower order foundational skills also critical for the development of fluent reading. Although there is no one exact sequence in which letter sounds should be introduced, targeted practice of letter sounds should begin with the letters that are most common and can be used to form simple words. (See Table 1) As soon as several letter sounds are mastered, the letters should be combined to form simple words. Typically, most students learn the sounds of letters with sufficient repetition but experience difficulty blending sounds to form words (i.e., sounding out) because sounding out requires that students apply both PA (blending) and letter-sound knowledge to identify a printed word. With consistent practice with words that gradually increase in difficulty, students with LD and students with ID will become fluent with these skills. The goal is for students to practice sounding out words until they are able to identify the word without sounding out (i.e., unitization). As students with ID begin to learn a set of words, it is sometimes necessary to explicitly teach students to use the sounding out procedure only when they do not already recognize a word. In Table 1, we provide a list of words that are common (i.e., high frequency) and that are regularly spelled. As students are able to quickly identify the easier words (i.e., within $2-3$ seconds), they should progress to more difficult words.

\section{Irregular Words}

Of course, many common words are irregularly spelled and cannot be sounded out (See Table 1). The goal for these words is also unitization; however, in this case, the sounding out strategy is not effective. Activities that require students to attend to the spellings of irregular words enable students to unitize these words. There is no exact sequence in which these words should be introduced, but the principle is that the most frequent words should be introduced early, as they will be found most frequently in early text and will be easier to link to meaningful activities. The words listed in Table 1 were selected based on their frequency and their ability to be combined to form simple sentences. As soon as students recognize a small number of decodable and irregular words, simple activities can be developed to give students practice reading these words in context. The principle again is to repeat simple tasks, gradually increase the difficulty of the task, and integrate the task with other tasks. For example, if the teacher gave the student the words little, dog, ran, the, and fast, the student could combine the words to create the sentence, The little dog ran fast. In completing this simple activity, the student is practicing the identification of the words in a meaningful task that requires basic comprehension skills.

\section{Morphemes and Multisyllabic Words}

As students increase their ability to identify single-syllable words, they should begin to learn more complex words, progressing from words with inflectional endings (-s, -ed, -ing) to multisyllabic words composed of taught syllable types and finally to common affixes and root words. As with the other instructional strands, these skills should be taught explicitly, repetitively, and in a meaningful context. Easier skills should be mastered before moving to more difficult, complex skills. These words should be applied in context. For example, common root words and affixes should be taught explicitly. Then, during passage reading, words with affixes that are not pronounced correctly should be noted by the teacher, who can then provide additional instruction before the passage is read again. Effective teachers alternate between isolated, focused practice and application of skills in text.

\section{Passage Reading}

Practice with brief passages should begin as soon as students recognize enough words to successfully read simple books and passages. With sufficient support, at-risk students and students with LD should begin this process by the middle of first grade. The goals for students with ID will 


\section{TABLE 1}

Recommended Sequence of High Frequency Words

Decodable Words

Irregular Words

Simple CVCC words (vowels a, i, o; common consonants, sh)

Very frequent and useful irregular words

\begin{tabular}{|c|c|c|}
\hline am & dad & hill \\
\hline an & did & him \\
\hline and & dog & hop \\
\hline ask & fast & hot \\
\hline at & fat & if \\
\hline back & fish & in \\
\hline bag & got & it \\
\hline big & had & its \\
\hline $\mathrm{Cl}$ & hand & land \\
\hline cat & hat & last \\
\hline
\end{tabular}

CVCC/CCVC words (all single letters; sh, and th)

Frequent and useful irregular words

$\begin{array}{cccccccc}\text { be } & \text { get } & \text { men } & \text { step } & \text { this } & \text { any } & \text { his } & \text { very } \\ \text { bed } & \text { go } & \text { much } & \text { still } & \text { up } & \text { as } & \text { into } & \text { want } \\ \text { best } & \text { he } & \text { must } & \text { stop } & \text { us } & \text { do } & \text { like } & \text { was } \\ \text { box } & \text { help } & \text { next } & \text { such } & \text { well } & \text { does } & \text { many } & \text { where } \\ \text { bus } & \text { hen } & \text { no } & \text { sun } & \text { went } & \text { door } & \text { one } & \text { who } \\ \text { but } & \text { jump } & \text { pet } & \text { tell } & \text { when } & \text { find } & \text { put } & \text { your } \\ \text { cut } & \text { just } & \text { red } & \text { ten } & \text { which } & \text { good } & \text { there } & \\ \text { duck } & \text { left } & \text { run } & \text { than } & \text { with } & & & \\ \text { end } & \text { leg } & \text { set } & \text { that } & \text { yes } & & & \\ \text { fox } & \text { let } & \text { six } & \text { them } & & & & \\ \text { fun } & \text { me } & \text { stand } & \text { then } & & & \end{array}$

Long vowel and r-controlled words; more common irregular words

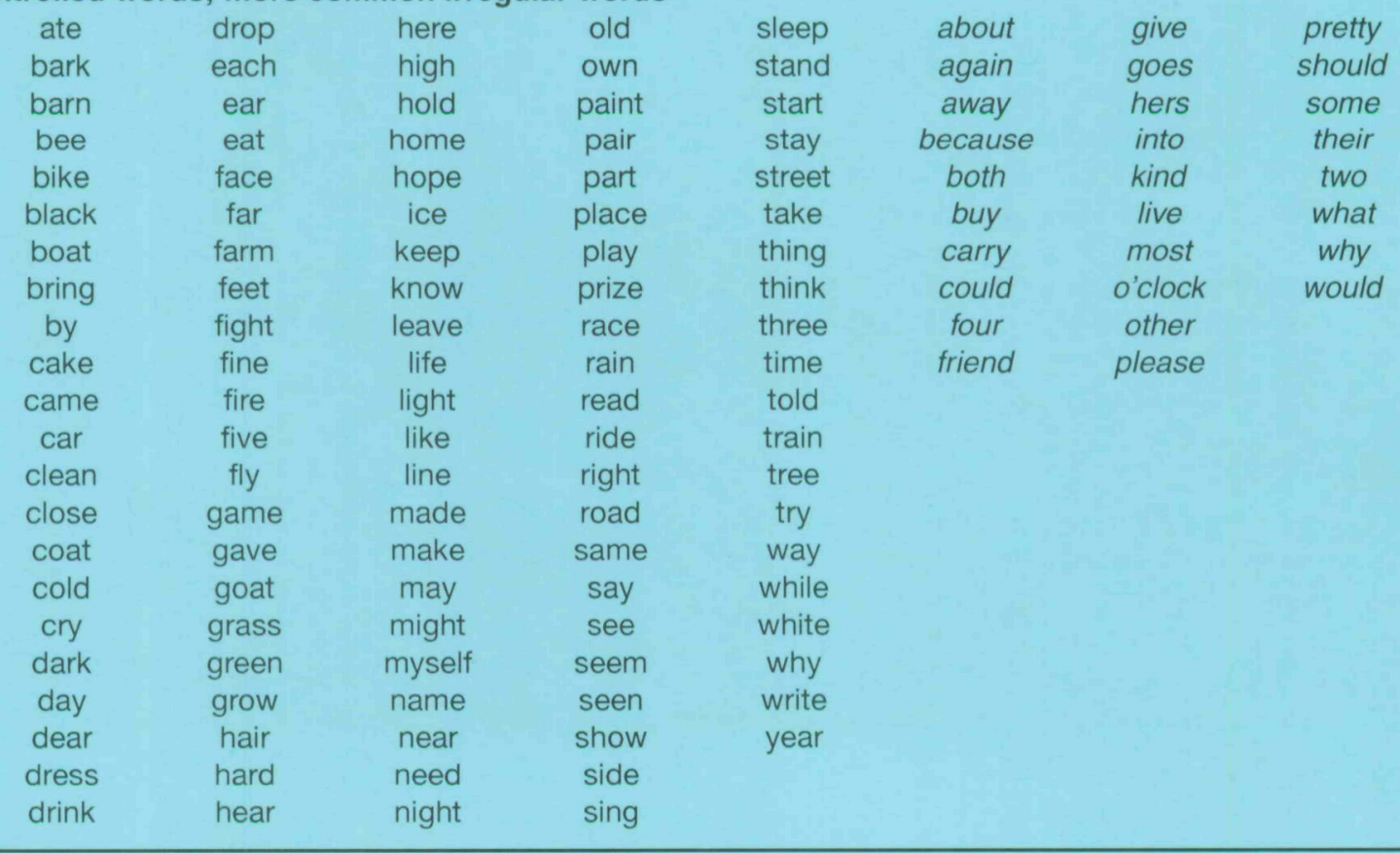


vary depending on the rate of growth for individual students (see Allor, Mathes, Roberts et al., 2010, and Allor Mathes, Champlin, \& Cheatham, 2009, for discussion). Selecting motivating text at an appropriate difficulty level is always challenging, but it is a critical factor in planning fluency instruction and practice. Leveled systems and Lexile scores (see Stenner, Burdick, Sanford, \& Burdick, 2006) are helpful tools for teachers, but these should not replace quick oral reading checks to determine whether students are reading with at least $90 \%$ accuracy. Alternative passages should always be available in case a selected passage is either too difficult or too easy for a student. Care should be taken not to discourage a child if a selected passage is too difficult. Instead of focusing on the difficulty of the passage or the errors the student is making, other options are to simply ask the student whether he or she would prefer to read something different or to say that this book was not a good choice and that another book would be better practice. Although a variety of techniques have been developed, passage reading that targets fluency development typically includes some combination of modeling by a skilled reader, providing feedback, reading short passages or books, and rereading.

Modeling and feedback are two important considerations when planning for passage reading that targets fluency development. Research supports the regular use of modeling of passage reading during fluency instruction. Students need to hear fluent reading frequently so they become familiar with the prosodic features of fluent reading, including rhythm, intonation, stress, and other expressive attributes of reading. These attributes vary with different types of text (e.g., narrative genres, expository text); therefore, students need to hear modeling with a variety of text types. They also need to be explicitly taught to attend to these various features so they can clearly understand that the goal of fluent reading is reading at a comfortable pace with natural sounding language that allows the listener to better understand the story. Feedback about prosody should be provided to students regularly so they are aware of their progress and areas still needing improvement.

Corrective feedback regarding word-reading errors should also be provided regularly. How this feedback is provided may vary depending on the circumstances and who is supporting student practice. Teachers may choose to stop students immediately when an error is made and provide assistance or make notes of errors and address these errors immediately after a passage is read. If the errors are frustrating to the student or obviously impeding comprehension, it is usually best to assist the student immediately. If not, concentrated practice of words missed, followed by rereading of the passage, often works well. If someone other than the teacher (a peer, volunteer, etc.) is supporting the student, then it is usually best to use a consistent simple procedure each time an error is made (e.g., stop the student, supply the correct word, and have the student reread the sentence).
Research also supports the regular use of repeated reading during fluency instruction. A variety of specific routines have been studied, but the comment element is that all involve reading a passage two or more times. One technique included in peer tutoring research involves pairing a somewhat higher performing peer with a lower performing peer (Fuchs \& Fuchs, 2005; Mathes, Howard, Allen, \& Fuchs, 1998). The higher performing peer reads a text for 5 minutes, and then the lower performing peer reads that same text again for 5 minutes. Each peer follows along and corrects errors, if any, while the partner reads. Somewhat surprisingly, in this setting even lower performers are often able to identify the oral reading errors made by their peer. Listening to the higher performing peer allows the lower performing peer to hear appropriate modeling of prosody, comprehend the text before reading it independently, and hear the correct pronunciation of any unfamiliar words.

Another repeated reading technique that teachers commonly use includes listening to the teacher model, independently reading, and then reading orally to the teacher. One day the teacher reads a selection orally to the class. Then, on a subsequent day, the students are assigned one or more pages to practice independently before reading some portion of the passage to the teacher, either individually or in a small group. The final oral reading provides the teacher with an opportunity to monitor progress as well as provide specific feedback and further scaffolding.

Gradually, the amount of independent and silent reading should increase; however, this should be monitored carefully to ensure that students are reading appropriate texts with success. Currently, evidence does not link independent reading practice with reading fluency (National Reading Panel, 2000); therefore, instructional time should focus on guided or scaffolded reading practice. As already described, reading with a peer can be a very effective supplement to teacher-supported fluency instruction. Silent reading should be carefully monitored with quick comprehension checks. When students are accustomed to being held accountable for their independent reading, they are more likely to focus on meaning as they read. Although comprehension checks may include traditional questioning about the text read, other options include brief meaningful discussions, retelling, and written responses. Skillful teachers can quickly ascertain how well a student comprehended a text by asking a basic starter question (e.g., Did you enjoy reading the story? Why or why not?) and then engaging the student in a brief discussion, asking prompting questions as needed. Alternatively, students may briefly retell a story orally or write brief written responses to text. For example, written responses to the text might include a short summary and why the student does or does not recommend the text to others.

Wide reading for pleasure should be strongly encouraged, though students with disabilities may require support during reading until their word recognition skills are well 
developed. Students with disabilities are most often reluctant to read for pleasure and frequently experience difficulty in selecting appropriate texts that are interesting to them. In short, the process of selecting books and reading independently are negative experiences for many students with disabilities. Making these experiences positive requires a lot of effort, but the outcome may be life changing for a student. The first step is helping the student select reading material that is motivating and not too difficult. Encourage students to try a variety of materials, ranging from traditional trade books to graphic novels to magazines. Check frequently to see whether students are enjoying what they are reading and make new recommendations, as needed.

\section{CONCLUSION}

Helping students with disabilities become fluent readers is a complex and challenging task that begins as soon as reading instruction begins. Automaticity with lower level word recognition processes is an essential component of fluent reading, but learning to read fluently involves more than simply saying words accurately and quickly. It also includes learning to read with expression that reflects and enables deep comprehension of text. Throughout this article we have emphasized the reciprocal relationship between comprehension and fluency development. Not only does fluency make comprehension possible, but comprehension also improves fluency. Truly fluent reading is expressive and does not occur in the absence of comprehension. As is evident in Perfetti's model, when a skilled reader reads, many different processes are working together to result in deep understanding of a passage (Perfetti et al., 2005). Therefore, we recommend embedding fluency instruction in meaningful contexts as much as possible. Even when practicing lower order skills, students need to be cognizant that the overall purpose of reading is always comprehension. Successful programs for students with disabilities do include isolated practice of letters, sounds, and words, but they also integrate these into meaningful contexts as quickly as possible. Letters should be connected to words and words connected to their individual meanings and then applied to passages. When word recognition skills are connected to meanings, students will then be more likely to comprehend what they read.

\section{REFERENCES}

Adams, M. J. (1990). Beginning to read: Thinking and learning about print. Cambridge: Massachusetts Institute of Technology.

Allor, J. H., Champlin, T. M., Gifford, D. B., \& Mathes, P. G. (2010). Methods for increasing the intensity of reading instruction for students with intellectual disabilities. Education and Training in Autism and Developmental Disabilities, 45, 500-511.

Allor, J. H., Mathes, P. G., Champlin, T. M., \& Cheatham, J. P. (2009). Research-based techniques for teaching early reading skills to students with intellectual disabilities. Education and Training in Developmental Disabilities, 44, 356-366.

Allor, J. H., Mathes, P. G., Jones, F. G., Champlin, T. M., \& Cheatham, J. P. (2010). Individualized research-based reading instruction for students with intellectual disabilities. TEACHING Exceptional Children, 42, 6-12.
Allor, J. H., Mathes, P. G., Roberts, J. K., Cheatham, J. P., \& Champlin, T. M. (2010). Comprehensive reading instruction for students with intellectual disabilities: Findings from the first three years of a longitudinal study. Psychology in the Schools, 47, 445-466.

Baumann, J. F., \& Kame'enui, E. J. (Eds.). (2004). Vocabulary instruction: Research to practice. New York: Guilford Press.

Carnine, D. W., Silbert, J., Kame'enui, E. J., \& Tarver, S. G. (2004). Direct instruction reading (4th ed.). Upper Saddle River, NJ: Pearson Merrill Prentice Hall.

Chard, D. J., \& Harn, B. (2008) Project CIRCUITS: Center for improving reading competence using intensive treatments schoolwide. In C. R. Greenwood, T. R. Kratochwill, \& M. Clements (Eds.), Schoolwide Prevention Models (pp. 143-172). New York: Guilford.

Chard, D. J., Pikulski, J. J., \& McDonagh, S. H. (2006). Fluency: The link between decoding and comprehension for struggling readers. In T. Rasinski, C. Blachowicz, \& K. Lems (Eds.), Fluency instruction: Research-based best practices (pp. 39-61). New York, NY: Guilford Press.

Ehri, L. C. (2005). Learning to read words: Theory, findings, and issues. Scientific Studies of Reading, 9(2), 167-188.

Fuchs, D. \& Fuchs, L. S. (2005). Peer-assisted learning strategies: Promoting word recognition, fluency, and reading comprehension in young children. The Journal of Special Education, 39(1), 34.

Good, R. H., \& Kaminski, R. A. (2002). Dynamic indicators of basic early literacy skills, (6th ed.). Retrieved from http://dibels.uoregon.edu/

Kame'enui, E. J., Carnine, D. W., Dixon, R. C., Simmons, D. C., \& Coyne, M. D. (2002). Effective teaching strategies that accommodate diverse learners (2nd ed.). Upper Saddle River, NJ: Merrill Prentice Hall.

Mathes, P., Howard, J., Allen, S., \& Fuchs, D. (1998). Peer-assisted learning strategies for first-grade readers: Responding to the needs of diverse learners. Reading Research Quarterly, 33(1), 62-94.

National Reading Panel (2000). Teaching children to read: an evidence-based assessment of the scientific research literature on reading and its implications for reading instruction (NIH Pub. No. 00-4769). Washington, DC: Author.

O'Connor, R. E. (2007). Teaching word recognition: Effective strategies for students with learning difficulties. New York: Guilford Press.

Perfetti, C. A. (1985). Reading ability. New York: Oxford University Press.

Perfetti, C. A., Landi, N., \& Oakhill, J. (2005). The acquisition of reading comprehension skill. In M. J. Snowling \& C. Hulme (Eds.), The science of reading: A handbook (pp. 227-247). Oxford: Blackwell.

Pikulski, J. J., \& Chard, D. J. (2005). Fluency: Bridge between decoding and reading comprehension. Reading Teacher, 58, 510-519.

Samuels, S. J. (2002). Reading fluency: Its development and assessment. In A. E. Farstrup \& S. J. Samuels (Eds.), What research has to say about reading instruction (pp. 166-183). Newark, DE: International Reading Association.

Stanovich, K. E. (1986). Matthew effects in reading: Some consequences in individual differences in the acquisition of literacy. Reading Research Quarterly, 21, 360-407.

Stanovich, K. E. (2000). Progress in understanding reading: Scientific foundations and new frontiers. New York: Guilford Press.

Stecker, S. K., Roser, N. L., \& Martinez, M. G. (1998). Understanding oral reading fluency. In T. Shanahan \& F. V. Rodriguez-Brown (Eds.), 47th yearbook of the National Reading Conference (pp. 295-310). Chicago: National Reading Conference.

Stenner, A. J., Burdick, H., Sanford, E. E., \& Burdick, D. S. (2006). How accurate are lexile text measures? Journal of Applied Measurement, 7(3), 307-322.

Tallal, P., Merzenich, M., Jenkins, W. M., \& Miller, S. L. (1999). Moving research from the laboratory to clinics and classrooms. In D. D. Duane (Ed.), Reading and attention disorders (pp. 93-112). Baltimore: York Press.

Wagner, R. K., \& Torgesen, J. K. (1997). The nature of phonological processing and its causal role in the acquisition of reading skills. Psychological Bulletin, 101, 192-212. 